\title{
Even Mild Changes in Free Thyroxine Could Influence the Degree of Heart Failure Measured by Its Biological Surrogates
}

\author{
O. MAYER JR ${ }^{1}$, J. S̆IMON $^{1}$, J. ČECH ${ }^{1}$, H. ROSOLOVÁ ${ }^{1}$, J. HRBKOVÁ $^{1}$, R. PIKNER $^{1}$, \\ L. TREFIL ${ }^{2}$ \\ ${ }^{1}$ Centre of Preventive Cardiology, Second Department of Internal Medicine, Charles University, \\ Medical Faculty, Pilsen, ${ }^{2}$ Department of Clinical Biochemistry and Hematology, University \\ Hospital, Pilsen, Czech Republic
}

Received December 1, 2006

Accepted May 18, 2007

On-line July 26, 2007

\begin{abstract}
Summary
Both, severe hypo- or hyperthyroidism may alter hemodynamic parameters. The aim of our study was to ascertain, whether also distinct changes within normal range of free thyroxine (fT4) would be associated with an impairment of left ventricle function in patients with chronic heart failure. Hundred-forty-eight patients ( $m 121, \mathrm{f} 27$, mean age $63.8 \pm 1.14$ years) with chronic heart failure, fT4 levels within the normal range (9-22 pmol/l) and without thyrostatics or substitution treatment. Degree of heart failure was quantified by plasma B-type natriuretic peptide (BNP) and N-terminal pro-BNP (NT-proBNP). Patients with fT4 in the range $11.9-14.6 \mathrm{pmol} / \mathrm{l}$ [optimal, $2^{\text {nd }}-3^{\text {th }}$ quintile] had significantly lower NT-proBNP $(718 \pm 70.4 \mathrm{pg} / \mathrm{ml})$, than those with fT4 $\leq 11.8$ [low-normal, bottom quintile] $(1236 \pm 223.6 \mathrm{pg} / \mathrm{ml}$; $\mathrm{p}<0.03$ ) and those with fT4 over $14.6 \mathrm{pmol} / \mathrm{l}$ [high-normal, top two quintiles] $(1192 \pm 114.9 \mathrm{pg} / \mathrm{ml} ; \mathrm{p}<0.0002)$. These differences remain significant, also if adjusted for age, gender and other confounders; adjusted odds ratio was 1.30 (1.05-1.59) for optimal vs. low-normal and 1.27 (1.04-1.55) for optimal vs. highnormal. Similar statistical differences were also found in BNP, but only when optimal and high-normal fT4 ranges were compared. In conclusion, the severity of heart failure seems to be also influenced by only mild deviations of fT4 concentrations from optimal levels.
\end{abstract}

\section{Key words}

Thyroxine - High-normal • Low-normal • Heart failure • Natriuretic peptides

\section{Corresponding author}

O. Mayer Jr, Centre of Preventive Cardiology, Second Department of Internal Medicine, E. Beneše 13, 30605 Plzeň (Pilsen), Czech Republic. Fax: +420 377402929. E-mail: mayerjr@lfp.cuni.cz

\section{Introduction}

Thyroid hormones have many effects on the cardiovascular system. It is evident, that thyroid dysfunction may accelerate atherosclerosis through some conventional cardiovascular risk factors (dyslipidemia, hypertension), but thyroid status also has a close link to several hemodynamic parameters (Feldman et al. 1986, Klein et al. 1990, Bengel et al. 2000, Biondi et al. 2002, Ripoli et al. 2005). Triiodothyronine plays a direct role in the modulation myocardial contractile status by upregulation of heavy alfa and beta chains of myosin, regulation of the activity of Na,K-ATPase, calciumactivated ATPase in sarcoplasmatic reticulum (SERCA II) and voltage-regulated calcium channels. Moreover, it also regulates the activity of beta receptors (Klein et al. 1990, Biondi et al. 2002ab). Triiodthyronine decreases peripheral vascular resistance, increases peripheral oxygen consumption and oxygen demand of myocardial tissue, especially under stress condition (Bengel et al. 2000, Biondi et al. 2002ab, Ripoli et al. 2005). Pathophysiologically, thyroid dysfunction leads to an impairment of the isovolemic relaxation and filling of the left ventricle, and to an impairment of the myocardial contractility, decrease of stroke volume and ejection fraction (Feldman et al. 1986, Biondi et al. 2002ab, Ripoli et al. 2005). Clinical consequences of all these pathophysiological processes may result in heart failure.

Impairment of cardiac function has already been observed in patients with clinically manifest hypoor hyperthyroidism., However, inconsistent findings were 
reported in subclinical thyroid dysfunctions. The aim of this study was to ascertain whether mild changes of free thyroxine concentration (fT4) were associated with an impairment of left ventricle function (quantified by respective biological markers) in patients with clinically manifest chronic heart failure (CHF).

\section{Methods}

The study sample consisted of patients with clinically manifest, chronic congestive heart failure, examined within the frame of EuroHeart Failure survey. Selection criteria and standard examination protocol of this multicentric program were in detail described elsewhere (Cleland et al. 2000, Rosolová et al. 2005). Briefly, patients consecutively hospitalized during a timespan of 12 months for congestive heart failure or at discharge treated for this condition, were selected. Only patients from the Pilsen center of EuroHeart Failure survey were included into the present analysis (they represent about $30 \%$ of the Czech sample of EuroHeart Failure survey). Patients with free thyroxin concentration outside normal limits $(9-22 \mathrm{pmol} / \mathrm{l})$ and/or on thyrostatics or L-thyroxin substitution were excluded. Information of personal and demographic characteristics, personal and family history of coronary heart disease, life-style and current pharmacotherapy were obtained at interview. Following standardized examinations were performed. Height and weight were measured in light indoor clothes without shoes using SECA 707 scales and measuring stick. Blood pressure was measured twice in the sitting position on the right arm, using standard mercury sphygmomanometer, with a precision of $2 \mathrm{~mm} \mathrm{Hg}$. All used devices (i.e. scale and sphygmomanometer) were calibrated at the start of survey using appropriate standard procedures and by manufacturer reference. Venous blood samples were drawn after minimally $12 \mathrm{~h}$ overnight fast. Total, HDL and LDL cholesterol as well as triglycerides and glycemia were determined in fresh blood specimens by commercial kits (Unimate, Roche Diagnostics, Manheim, Germany) on Cobas Mira S Autoanalyser (Roche Diagnostics). Blood concentrations of thyroid stimulating hormone (TSH), FT4, total homocysteine (tHcy) and B-type natriuretic peptide (BNP) were estimated from frozen specimens $\left(-80^{\circ} \mathrm{C}\right)$ by commercial FPIA kits (Abbott Diagnostics, Wiesbaden, Germany) on AxSYM analyzer. Intra-individual variability of these estimations was less than $2 \%$. N-terminal pro-BNP (NT-proBNP) was estimated using ELISA commercial
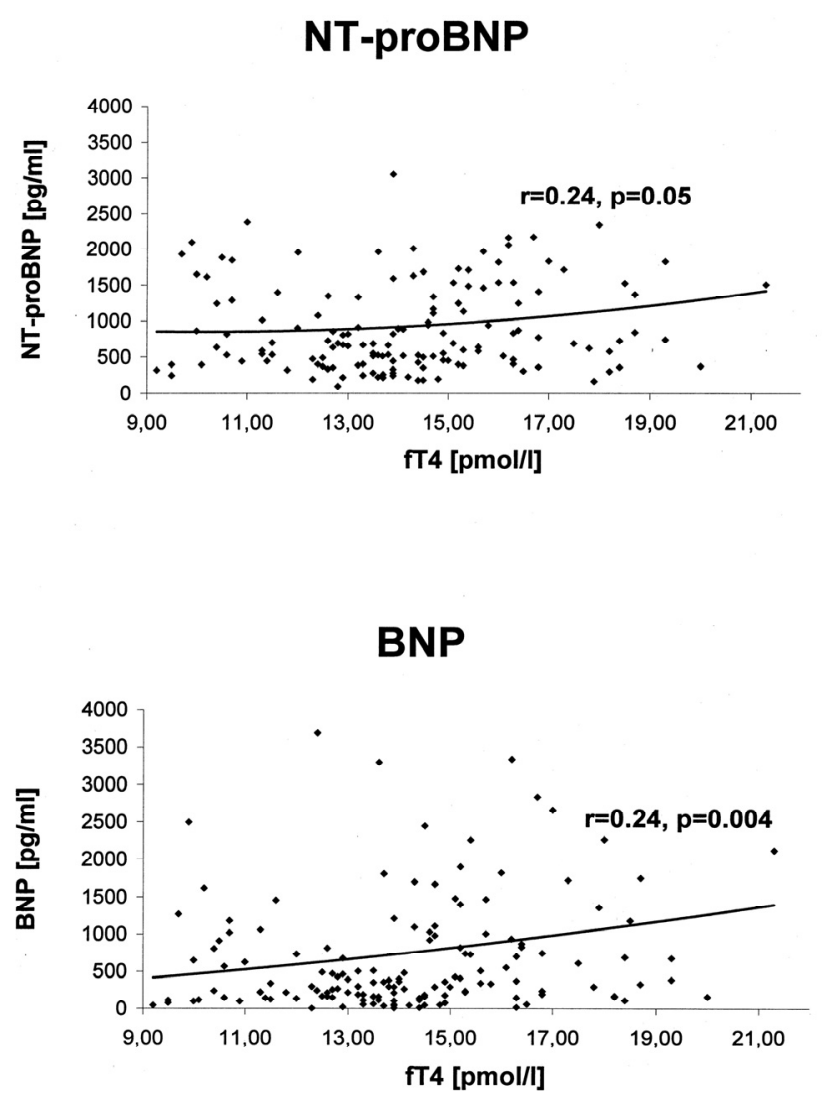

Fig. 1. Correlation between free thyroxine concentrations and nautriuretic peptides by Spearman's correlation [correlation coefficient, $p$ value].

kits (Biomedica, Vienna, Austria), with coefficients of variation less than $6 \%$. For statistical evaluation STRATA 6 software was used. Mann-Whitney U test, Spearman correlation, Fisher Chi square and multiple logistic regression were calculated when necessary. All procedures were done according to Good Clinical Practice regulation and were approved by the local Ethical Committee. The informed consent was obtained from all subjects and all personal data were stored under the provisions of the Czech Data Protection Act.

\section{Results}

A total of 148 patients, 121 males and 27 females were included into this analysis. Personal and medical history, anthropometrical and biochemical characteristics of the study sample are given in Table 1. Correlations between fT4 concentrations and natriuretic peptides are shown in Figure 1. Free thyroxine concentration was significantly positively associated with NT-proBNP and BNP in a continuous manner (Fig. 1). 
Table 1. Basic characteristics of the study sample

\begin{tabular}{|c|c|}
\hline Number (males/females) & $148(121 / 27)$ \\
\hline Age (years) & $59.1 \pm 11.58$ \\
\hline Current smoking (\%) & 8.0 \\
\hline Current or ex-smoking (\%) & 70.0 \\
\hline Etiology of heart failure & \\
\hline$(C H D / H P T / I C M P, \%)$ & $66 / 17 / 18$ \\
\hline Heart failure treatment proportion $(\%)$ : & \\
\hline - Diuretics & 34 \\
\hline - ACE inhibitors or ATII antagonists & 93 \\
\hline - Beta-blockers & 51 \\
\hline - Digoxin & 34 \\
\hline - Spironolacton & 61 \\
\hline Lipid-lowering treatment (\%) & 18 \\
\hline Antidiabetics (\%) & 30 \\
\hline Body mass index $\left(\mathrm{kg} / \mathrm{m}^{2}\right)$ & $28.9 \pm 12.16$ \\
\hline Systolic blood pressure ( $\mathrm{mmHg}$ ) & $120.6 \pm 16.63$ \\
\hline Diastolic blood pressure ( $\mathrm{mmHg}$ ) & $72.7 \pm 7.24$ \\
\hline Total cholesterol (mmol/l) & $6.94 \pm 13.57$ \\
\hline HDL cholesterol (mmol/l) & $1.34 \pm 1.266$ \\
\hline Triglycerides $(\mathrm{mmol} / \mathrm{l})$ & $1.76 \pm 1.984$ \\
\hline Glycaemia (mmol/l) & $6.73 \pm 4.92$ \\
\hline Total homocysteine $(\mu \mathrm{mol} / \mathrm{l})$ & $14.62 \pm 6.31$ \\
\hline thyreostimulating hormone $(\mathrm{mU} / \mathrm{l})$ & $2.36 \pm 4.47$ \\
\hline free thyroxine $(\mathrm{pmol} / \mathrm{l})$ & $12.65 \pm 3.34$ \\
\hline$N$-terminal proBNP $(\mathrm{pg} / \mathrm{ml})$ & $956.9 \pm 843.80$ \\
\hline$B N P(p g / m l)$ & $967.6 \pm 841.88$ \\
\hline
\end{tabular}

Data are means $\pm \mathrm{SD}$ or prevalence. $\mathrm{CHD}$, coronary heart disease; HPT, arterial hypertension; ICMP, idiopatic cardiomyopathy; $\mathrm{ACE}$, angiotensine converting enzyme; ATII, angiotensine II; $\mathrm{HDL}$, high density lipoprotein; BNP, B-type of natriuretic peptide

The study sample was divided into three categories according to fT4 concentrations: low-normal fT4 (9-11.8 pmol/1, i.e. $1^{\text {st }}$ quintile), optimal fT4 (11.9$14.6 \mathrm{pmol} / 1$, i.e. $2^{\text {nd }}$ and $3^{\text {rd }}$ quintiles) and high-normal fT4 (14.7-22 pmol/1, i.e. $4^{\text {th }}$ and $5^{\text {th }}$ quintiles). Patients with low-normal fT4 were statistically significantly younger than those with optimal fT4 concentration (58.5 vs. 64.9 years; $p=0.03$ ), while patients with high-normal fT4 significantly lower body mass index (26.3 vs. 31.0 $\left.\mathrm{kg} / \mathrm{m}^{2} ; \mathrm{p}=0.003\right)$ and higher TSH level (1.15 vs. 1.66 $\mathrm{mU} / \mathrm{l} ; \mathrm{p}=0.003$ ). In terms of other characteristics (Table 1), except natriuretic peptides we did not find any significant differences. Differences in BNP and NTproBNP among these defined fT4 categories are depicted in Figure 2. Patients with low-normal fT4 showed significantly higher levels of NT-proBNP, as compared to subjects with optimal fT4. On the other hand, high-
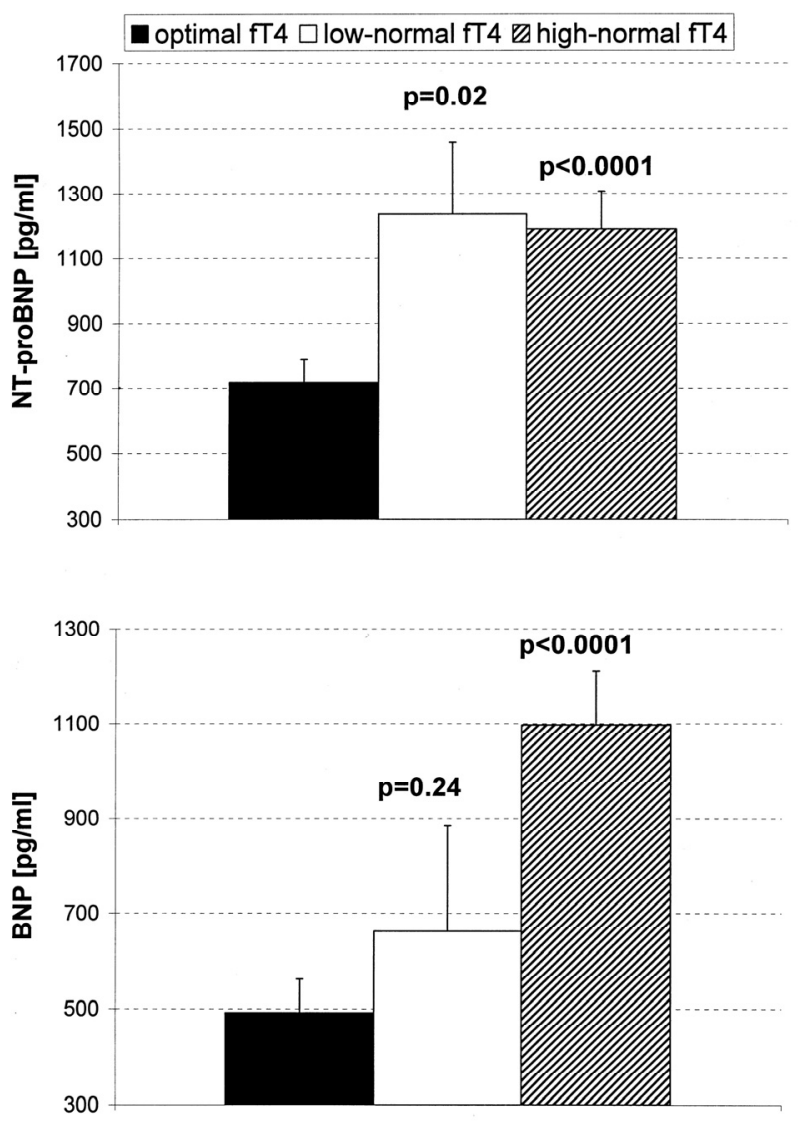

Fig. 2. Concentrations of natriuretic peptides according to stratified free thyroxine (optimal, low-normal and high normal by definition) [mean \pm SEM, p value by Mann-Whitney $U$ test].

normal fT4 patients were observed to have a significant increase in both NT-proBNP and BNP (Fig. 2), when compared to patients with optimal fT4. The significance of these differences also remains, if adjusted for potential confounders (age, gender, body mass index, systolic blood pressure, total cholesterol, glycaemia and homocysteine) (Table 2) by multiple logistic regression. Taking the relative risk of increase in natriuretic peptides in patients with optimal fT4 equal to 1 , patients with lownormal fT4 showed a significant $30 \%$ risk of increased NT-proBNP. Similarly, patients with high-normal fT4 showed significant odds ratio of increased NT-proBNP and BNP (1.27 and 1.26, respectively).

\section{Discussion}

In this study we found that even mild changes of fT4, still within normal clinically accepted levels, may influence the burden of heart failure, quantified by its biological surrogates (ie. natriuretic peptides). This relationship between fT4 and natriuretic peptides had a $\mathrm{J}$ shape distribution. Lowest degree of heart failure was 
Table 2. Adjusted relative risk of increased natriuretic peptides in association with stratified free thyroxine concentrations, ie. optimal fT4 (11.9-14.6 pmol/l), low-normal fT4 (9-11.8 pmol/l) and high-normal fT4 (14.7-22 pmol/l) [Odds ratio (95\% confidence intervals)]

\begin{tabular}{lcc}
\hline & NT-proBNP & BNP \\
\hline optimal fT4 & 1 & 1 \\
low-normal fT4 & $\mathbf{1 . 3 0}(\mathbf{1 . 0 5}-\mathbf{1 . 5 9})$ & $1.12(0.84-1.41)$ \\
high-normal fT4 & $\mathbf{1 . 2 7}(\mathbf{1 . 0 4 - 1 . 5 5 )}$ & $\mathbf{1 . 2 6}(\mathbf{1 . 0 3 - 1 . 5 3 )}$ \\
\hline
\end{tabular}

multiple logistic regression; particular heart failure surrogates as dependent variables, adjusted for age, gender, body mass index, systolic blood pressure, total cholesterol, glycemia and homocysteine.

observed in the range of fT4 11.9-14.6 pmol/1 $\left(2^{\text {nd }}\right.$ and $3^{\text {rd }}$ quintiles). Concentrations of fT4 outside both ends of these limits (i.e. higher or lower) were associated with increased concentrations of heart failure surrogates, in spite that they still remained within accepted normal range of fT4. This association was more evident at highnormal fT4 levels, than at low normal, where only the increase of a more sensitive marker (NT-proBNP) was observed.

The impairment of left ventricular function is well-known in patients with overt hypo- or hyperthyroidism, but the evidence is lacking or not verified in patients with mild (subclinical) forms of thyroid dysfunction. Hemodynamic alterations measured by echocardiography or MRI were disclosed in patients after total thyroidectomy for thyroid cancer who have not been substituted with thyroid hormones and who developed a severe secondary hypothyroidism (Bengel $e t$ al. 2000). In comparison to controls, decreased left ventricular end-diastolic volume, cardiac index and increased vascular resistance (measured by MRI) were reported in subjects with still normal fT4, but already increased TSH (Ripoli et al. 2005).

Left ventricular dysfunction was also commonly observed in patients with overt hyperthyroidism. A shortterm elevation of thyroid hormones resulted in an increase in myocardial contractility and cardiac output, partly because of tachycardia, whereas long-term elevation resulted again into heart failure. It was reported (Wei et al. 2005) that patients with overt hyperthyroidism have six times higher BNP levels, than controls. Several case-reports observed left ventricle dilatation and low ejection fraction in patients with active Graves-Basedow thyreotoxicosis (Boccalandro et al. 2003). Important pathophysiological mechanism of heart failure in chronic overt hyperthyroidism are probably associated with histological changes in myocardium and left ventricle hypertrophy. Overt hyperthyroidism was reported to produce focal necrosis and fibrosis of myocardial cells (Callas and Hayes 1974). Recent experimental study in hamsters revealed an increase of left ventricular diameter and a decrease of ejection fraction only after two months of application of thyroid hormones. Similarly, several clinical studies reported that an excessive increase of thyroid hormones, usually present in clinically manifest thyreotoxicosis, produces left ventricular hypertrophy and dilatation (Ching et al. 1996, Kuzman et al. 2005).

There is rather limited evidence, whether normalization of thyroid status by thyroid hormones or thyrostatics also improves hemodynamic parameters, namely in patients with less serious forms of thyroid dysfunction. It was reported in single cases that thyrostatics produced not only decrease of fT4 in patient with severe thyreotoxicosis (before thyroidectomy were done as a final solution), but also increase in ejection fraction and decrease of left ventricular dilatation (Boccalandro et al. 2003)

It is difficult to quantify cardiac dysfunction by clinical methods only. In our study we used the estimation of natriuretic peptides, which is now routinely available. B-type of natriuretic peptide is produced in the left ventricle under the conditions of increased wall stress. It enables to quantify heart failure in a continuous manner and has an evident prognostic potential (Cowie et al. 1997, Bettencourt et al. 2000, Hobbs et al. 2002).

The present study had several limitations. Beside relatively small sample size, the echocardiography was not routinely performed in the course of our study. Therefore, we cannot analyze the association between free thyroxine and ejection fraction.

In conclusion, in the present study we observed that patients with clinically manifest chronic heart failure have relatively lower concentrations of natriuretic peptides, if their fT4 concentration ranges in a narrow optimal level (by definition used). Nevertheless, our study is limited by its retrospective, observational design. Therefore, it only allowed us to speculate on potential benefit of thyrostatics or thyroid hormone supplementation in patients with heart failure and fT4 outside these optimal limits. On the other hand, these patients should deserve particular attention and a very careful standard therapeutic management of heart failure.

\section{Conflict of Interest}

There is no conflict of interest. 


\section{Acknowledgements}

The study was supported by Internal Grant Agency of the Czech Ministry of Health, grant 9333-3 and by research project of Ministry of Education No. 0021620819. The excellent technical assistance of Mrs. Jitka Nováková is also gratefully acknowledged.

\section{References}

BENGEL FM, NEKOLLA SG, IBRAHIM T, WENIGER C, ZIEGLER SI, SCHWAIGER M: Effect of thyroid hormones in cardiac function, geometry and oxidative metabolism assessed noninvasively by positron emission tomography and magnetic resonance imaging. J Clin Endocrinol Metab 85: 1822-1827, 2000.

BETTENCOURT P, FERREIRA A, DIAS P, PIMENTA J, FRIOES F, MARTINS L, CERQUEIRA-GOMES M: Predictors of prognosis in patients with stable mild to moderate heart failure. J Card Fail 6: 306-313, 2000.

BIONDI B, PALMIERI EA, LOMBARDI G, FAZIO S: Effects of subclinical thyroid dysfunction on the heart. Ann Intern Med 137: 904-914, 2002a.

BIONDI B, PALMIERI EA, LOMBARDI G, FAZIO S: Effects of thyroid hormones in cardiac function: the relative importance of heart rate, loading conditions and myocardial contractility in the regulation of cardiac performance in human hyperthyroidism. J Clin Endocrinol Metab 87: 968-974, $2002 b$.

BOCCALANDRO C, BOCCALANDRO F, ORLANDER P, WEI CF: Severe reversible dilated cardiomyopathy and hyperthyroidism: case report and review of the literature. Endocr Pract 9: 140-146, 2003.

CALLAS G, HAYES JR: Alterations in the fine structure of cardiac muscle mitochondria induced by hyperthyroidism. Anat Rec 178: 539-549, 1974.

CHING GW, FRANKLYN JA, STALLARD TJ, DAYKIN J, SHEPPARD M, GAMMAGE MD: Cardiac hypertrophy as a result of long-term thyroxine therapy and thyrotoxicosis. Heart 75: 363-368, 1996.

CLELAND JG, SWEDBERG K, COHEN-SOLAL A, COSIN-AGUILAR J, DIETZ R, FOLLATH F, GAVAZZI A, HOBBS R, KOREWICKI J, MADEIRA HC, PREDA I, VAN GILST WH, WIDIMSKY J, MAREEV V, MASON J, FREEMANTLE N, EASTAUGH J: The Euro Heart Failure Survey of the EUROHEART survey programme. A survey on the quality of care among patients with heart failure in Europe. Eur J Heart Fail 2: 123-132, 2000.

COWIE MR, STRUTHERS AD, WOOD DA, COATS AJ, THOMPSON SG, POOLE-WILSON PA, SUTTON GC: Value of natriuretic peptides in assessment of patients with possible new heart failure in primary care. Lancet 350: 1349-1353, 1997.

FELDMAN T, BOROW KM, SARNE DH, NEUMANN A, LANG RM: Myocardial mechanics in hyperthyroidism: importance of left ventricular loading conditions, heart rate and contractile state $J$ Am Coll Cardiol 7: 967-974, 1986.

HOBBS FD, DAVIS RC, ROALFE AK, HARE R, DAVIES MK, KENKRE JE: Reliability of N-terminal pro-brain natriuretic peptide assay in diagnosis of heart failure: cohort study in representative and high risk community populations. BMJ 324: 1498, 2002.

KLEIN I: Thyroid hormone and the cardiovascular system. Am J Med 88: 631-637, 1990.

KUZMAN JA, THOMAS TA, VOGELSANG KA, SAID S, ANDERSON BE, GERDES AM: Effects of induced hyperthyroidism in normal and cardiomyopathic hamsters. J Appl Physiol 99: 1428-1433, 2005.

RIPOLI A, PINGITORE A, FAVILLI B, BOTTONI A, TURCHI S, OSMAN NF, DE MARCHI D, LOMBARDI M, L'ABBATE A, IERVASI G: Does subclinical hypothyroidism affect cardiac pump performance. $J$ Am Coll Cardiol 45: 439-445, 2005.

ROSOLOVÁ H, ČECH J, ŠIMON J, ŠPINAR J, JANDOVÁ R, WIDIMSKY Sr J, HOLUBEC L, TOPOLČAN O: Short to long term mortality of patients hospitalised with heart failure in the Czech Republic - a report from the EuroHeart Failure Survey. Eur J Heart Fail 7: 780-783, 2005.

WEI T, ZENG C, TIAN Y, CHEN Q, WANG L: B-type natriuretic peptide in patients with clinical hyperthyroidism. J Endocrinol Invest 28: 8-11, 2005. 